\title{
Preparation of Protein materials for applications in photonics and bioelectronics
}

\author{
Niclas Solin ${ }^{1 *}$ \\ 1) Department of Physics, Chemistry, and Biology (IFM), Biomolecular and Organic Electronics, Linköping \\ University, 58183 Linköping, Sweden. \\ ${ }^{*}$ E-mail nicso@,ifm.liu.se
}

Natural materials often display hierarchical organization of nano-structures, lending unique properties to the macroscopic material. Many proteins are able to self-assemble into ordered nano/micro-structures, and it is interesting to investigate applications of such structures in materials science. However, for many applications it is desirable to have additional functionality, not present in the original protein. It is therefore desirable to develop methodology for functionalization of protein materials. We have developed novel techniques for preparation of functionalized protein materials. One extremely flexible and facile method involves co-grinding of a protein with a hydrophobic material. Upon exposure to appropriate stimuli the composite undergoes self-assembly into functionalized fibrils. The process can be performed simply with mortar and pestle [1-3] or with automated milling equipment [4]. These fibrils can then be induced to undergo colloidal assembly into materials. In this presentation will be given examples of such materials preparation, and applications of the materials in photonics and bioelectronics will be presented.

\section{References.}

[1] F. G. Bäcklund, J. Pallbo, N. Solin, Biopolymers 105, 249-259 (2016).

[2] F. G. Bäcklund, N. Solin, ACS Comb. Sci. 16, 721-729 (2014).

[3] F. G. Bäcklund, J. Wigenius, F. Westerlund, O. Inganäs, N. Solin, J. Mater. Chem. C 2, 7811-7822 (2014).

[4] L. Wang, N. Solin, J. Mater. Sci., 53, 13719-13732 (2018). 